\title{
Mesenchymal stem cell inhibition of T-helper 17 cell- differentiation is triggered by cell-cell contact and mediated by prostaglandin E2 via the EP4 receptor
}

\author{
Michelle M. Duffy ${ }^{1}$, Jana Pindjakova ${ }^{1}$, Shirley A. Hanley ${ }^{1}$, \\ Cathal McCarthy ${ }^{2}$, Gudrun A. Weidhofer ${ }^{1}$, Eva M. Sweeney ${ }^{1}$, Karen English ${ }^{3}$, \\ Georgina Shaw $^{1}$, J. Mary Murphy ${ }^{1}$, Frank P. Barry ${ }^{1}$, Bernard P. Mahon ${ }^{3}$, \\ Orina Belton ${ }^{2}$, Rhodri Ceredig ${ }^{1}$ and Matthew D. Griffin ${ }^{1}$ \\ ${ }^{1}$ Regenerative Medicine Institute (REMEDI), National Centre for Biomedical Engineering \\ Science (NCBES) and School of Medicine, Nursing and Health Sciences, National University of \\ Ireland, Galway, Galway, Ireland \\ ${ }^{2}$ School of Biomolecular and Biomedical Science, Conway Institute, University College Dublin, \\ Dublin, Ireland \\ ${ }^{3}$ Institute of Immunology, National University of Ireland, Maynooth, Maynooth, Co. Kildare, \\ Ireland
}

Mesenchymal stem cells (MSCs) inhibit T-cell activation and proliferation but their effects on individual T-cell-effector pathways and on memory versus naïve T cells remain unclear. MSC influence on the differentiation of naïve and memory $\mathrm{CD}^{+} \mathrm{T}$ cells toward the Th17 phenotype was examined. $\mathrm{CD} 4^{+} \mathrm{T}$ cells exposed to Th17-skewing conditions exhibited reduced CD25 and IL-17A expression following MSC co-culture. Inhibition of IL-17A production persisted upon re-stimulation in the absence of MSCs. These effects were attenuated when cell-cell contact was prevented. Th17 cultures from highly purified naïve- and memoryphenotype responders were similarly inhibited. Th17 inhibition by MSCs was reversed by indomethacin and a selective COX-2 inhibitor. Media from MSC/Th17 co-cultures contained increased prostaglandin E2 (PGE2) levels and potently suppressed Th17 differentiation in fresh cultures. MSC-mediated Th17 inhibition was reversed by a selective EP4 antagonist and was mimicked by synthetic PGE2 and a selective EP4 agonist. Activation-induced IL-17A secretion by naturally occurring, effector-memory Th17 cells from a urinary obstruction model was also inhibited by MSC co-culture in a COX-dependent manner. Overall, MSCs potently inhibit Th17 differentiation from naïve and memory T-cell precursors and inhibit naturally-occurring Th17 cells derived from a site of inflammation. Suppression entails cellcontact-dependent COX-2 induction resulting in direct Th17 inhibition by PGE2 via EP4.

Key words: Immunosuppression - Mesenchymal stem cells • Stem cells • T helper cells • Th17 cells

Supporting Information available online

\section{Introduction}

The immune suppressive properties of mesenchymal stem cells (MSCs) have garnered increasing attention over the past

Correspondence: Prof. Matthew D. Griffin e-mail: matthew.griffin@nuigalway.ie decade and constitute a central mechanism for MSC therapeutic benefits [1-4]. Specific modulatory effects of MSCs from human and experimental animal sources have been described for the differentiation, activation, proliferation and effector functions of multiple innate and adaptive immune cells [5-11]. Among these, MSC-mediated inhibition of primary T-cell activation and proliferation, suppression of DC maturation and promotion of regulatory phenotypes in 
monocyte/macrophages and $\mathrm{T}$ cells have been most extensively characterised [7-9, 11, 12].

In keeping with a paracrine or "trophic" model of MSC function in vivo [13], various MSC-produced soluble mediators have been implicated in these immunomodulatory effects including IL-10, IL-6, HGF, TGF- $\beta$, chemokine ligand-2 (CCL2), HLA-G, NO, tumor necrosis factor-inducible gene 6 protein (TSG-6), prostaglandin E2 (PGE2) and kyneurenine [1, 2, 7, 9, 12, 14-16]. For some such mediators, expression by MSCs may be dependent on pre-exposure to exogenous factors (e.g. IFN- $\gamma, \mathrm{TNF}$ ) or on contact-dependent MSC/target cell cross-talk [2, 7, 16-19]. The potential for harnessing MSC immunomodulatory properties has been highlighted by results in pre-clinical models of autoimmunity, allotransplantation, sepsis and acute ischemic injury $[1,4,7,14,15]$ as well as by outcomes from clinical trials in inflammatory bowel disease, graft-versus-host disease and myocardial infarction $[1,20]$.

$\mathrm{T}$ cells represent the primary effector cells for common autoimmune diseases and for rejection of transplanted organs and tissues [21]. Furthermore, activated memory $\mathrm{T}$ cells have been implicated in non-antigen-specific forms of tissue injury such as ischemia-reperfusion [22, 23]. In addition to the investigation of mechanisms underlying MSC inhibition of T-cell activation, attention has also been directed toward their influence on specific T-cell effector phenotypes including CD8 ${ }^{+}$CTLs and the Th1, Th2 and Treg sub-types of CD4 ${ }^{+} \mathrm{T}$ cells which may be more or less prominent in individual immune-mediated diseases [12, 24-26]. In vitro and in vivo experimental evidence would suggest that MSCs are consistently suppressive of CTL- and Th1mediated immune responses while being less inhibitory toward Th2-type responses and actively promoting Treg survival and expansion [9, 12, 27]. Less well understood for each of these subsets are the relative effects of MSCs on naïve T cells undergoing primary activation compared with previously activated, or memory-phenotype, $\mathrm{T}$ cells.

The recent description of an additional $\mathrm{CD}^{+}{ }^{+} \mathrm{T}$-cell subset, termed Th17 cells, has added further complexity to our understanding of cellular adaptive immunity [28]. The Th17 effector phenotype is characterised by synthesis of a signature cytokine, IL-17A, in addition to IL-17F, IL-21, IL-22 and CCL20 [29]. Th17 cells have been shown to mediate localised tissue inflammation as a defence against infection but also play a pathogenic role in immunological diseases including rheumatoid arthritis, multiple sclerosis, Crohn's disease, psoriasis and glomerulonephritis [28, 30, 31]. Th17 differentiation, activation and expansion are now known to be promoted by the combined influences of several cytokines including IL-6, TGF- $\beta 1$, IL-1, IL-21 and IL-23 [29]. To date, only a small number of studies have addressed the interaction between MSCs and Th17 cells with evidence emerging for both suppressive and augmenting effects of MSCs on this Th cell differentiation pathway [9, 14, 32-34].

In the current study, we extend the understanding of MSCmediated inhibition of Th17 cells and provide evidence for potential therapeutic benefits of MSC therapies in suppressing both de novo and ongoing pathogenic Th17 immune responses.

\section{Results}

\section{Dose- and contact-dependent inhibition of Th17 differentiation by MSCs}

C57BL/6 (B6) MSCs were co-cultured with $\mathrm{CD}^{+}{ }^{+} \mathrm{T}$ cells during primary activation under Th17-skewing conditions at ratios of $1: 2000-1: 20$. In these cultures, the day 4 concentration of IL-17A and the surface expression level of CD25 by CD4 ${ }^{+} \mathrm{T}$ cells were reduced in a dose-dependent manner (Fig. $1 \mathrm{~A}$ and $\mathrm{B}$ ). When re-stimulation of equal numbers of $\mathrm{CD}^{+}$cells retrieved from the cultures was carried out using anti-CD3/anti-CD28 beads, IL-17A production was lower for cells generated in the presence of MSCs (Fig. 1C). In multiple experiments, inhibition was consistently observed at MSC:T-cell ratios as low as 1:400. Although IFN- $\gamma$ has been reported to be necessary for triggering of maximal T-cell inhibitory effects of MSCs under some conditions [17, 19], omission of anti-IFN- $\gamma$ from the co-cultures was not associated with more potent Th17 suppression (Supplementary Fig. S2). The inhibitory effect of MSCs on Th17 activation was not strainspecific being demonstrable for MSCs from BALB/c and DBA mice (Supplemental Figs. S3A and S3B). Furthermore, B6 MSCs inhibited IL-17A production by BALB/c CD4 ${ }^{+} \mathrm{T}$ cells undergoing primary Th17 induction (Supplemental Fig. S3C).

A requirement for initial cell-cell contact was examined using Transwell ${ }^{\mathbb{R}}$ cultures in which $\mathrm{CD} 4^{+} \mathrm{T}$ cells undergoing primary Th17 induction in the lower compartment were separated from MSCs in the upper compartment. In these experiments, a modest reduction in the surface level of $\mathrm{CD} 25$ on $\mathrm{CD}^{+}{ }^{+} \mathrm{T}$ cells was observed at several MSC:T-cell ratios but reduction in IL-17A production following re-stimulation occurred only at the highest MSC:T-cell ratio (Fig. 2A and B). Consistently, comparable degrees of Th17 inhibition in cultures lacking direct T-cell/MSC contact required $\geq$ ten-fold greater MSC numbers than direct contact co-cultures.

\section{Inhibition of Th17 induction by MSCs occurs with both naïve- and memory-phenotype T-cell responders}

$\mathrm{CD}^{+} \mathrm{T}$ cells were purified by FACS into naïve- $\left(\mathrm{CD} 25^{-} / \mathrm{CD} 62 \mathrm{~L}^{\mathrm{hi}}\right)$ and memory- (CD25 $\left.5^{-} / \mathrm{CD} 2 \mathrm{~L}^{\mathrm{lo}}\right)$ phenotype populations (Fig. 3A) and were separately activated under Th17-skewing conditions. For both responder populations, co-culture with low numbers of MSCs (MSC:T-cell ratio 1:400) was associated with inhibition of CD25 up-regulation (Fig. 3B) and IL-17A production upon restimulation (Fig. 3C). Qualitatively similar results were observed in a total of five similar experiments with median proportionate inhibition of IL-17A production following re-stimulation of $26 \%$ (range 13-66\%) for memory-phenotype responders and 66\% (range 33-80\%) for naïve-phenotype responders. As shown in Fig. 4, co-culture of both naïve- and memory-phenotype $\mathrm{CD}^{+}$ $\mathrm{T}$ cells with a low ratio of MSCs was associated with a moderate anti-proliferative effect under Th17-skewing conditions using CFSE labelling (Fig. 4A) and a reduced proportion of $\mathrm{IL}_{-17 \mathrm{~A}^{+}}$ 

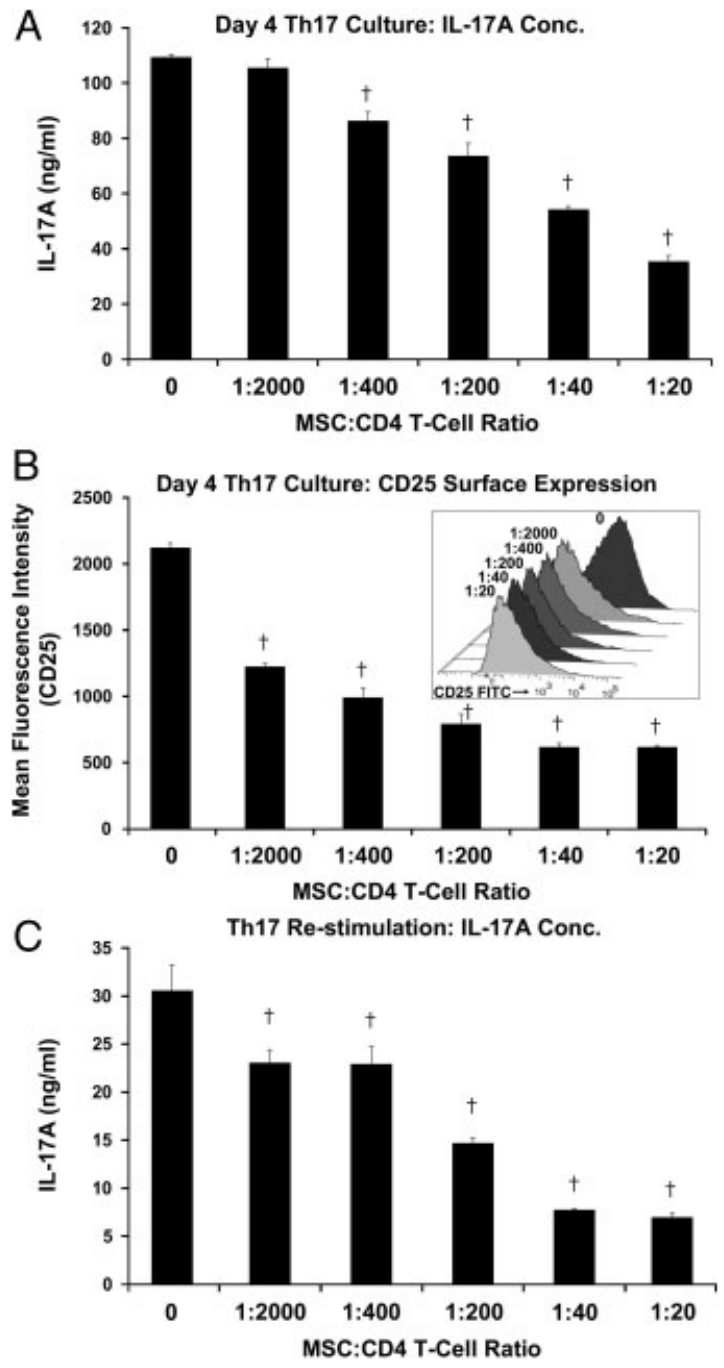

Figure 1. Inhibition of Th17 cell differentiation by MSCs. Purified B6 $\mathrm{CD}^{+} \mathrm{T}$ cells were activated with anti-CD3 $\varepsilon$ and splenic APCs under Th17-skewing conditions \pm B6 MSCs at the indicated ratios. Results are shown for (A) concentration of IL-17A in supernatants at day 4 as measured by ELISA, (B) surface expression level of CD25 on $\mathrm{CD}^{+}$ $T$ cells at day 4 (Insert: examples of anti-CD25 histograms) as measured by flow cytometry, and (C) IL-17A concentrations in supernatants of repurified $C D 4^{+} \mathrm{T}$ cells re-stimulated for $24 \mathrm{~h}$ with anti-CD3/anti-CD28coated beads. Data are mean $+\mathrm{SD}$ and are representative of five individual experiments. ${ }^{\dagger} p<0.05$ compared with no MSCs condition, two-tailed, unpaired Student's t-test.

cells within each generation of cell division using intracellular staining for IL-17A (Fig. 4B and C). It was concluded that the presence of low numbers of MSCs during a Th17-biased activation culture of either naïve or memory $\mathrm{CD}^{+} \mathrm{T}$ cells resulted in separate effects on $\mathrm{T}$-cell proliferation and on induction of high-level IL-17A production.

In additional experiments the specificity and direct nature of MSC suppression of Th17 differentiation was demonstrated. Inhibition of IL-17A secretion upon re-stimulation of Th17skewed naïve- and memory-phenotype $\mathrm{CD}^{+}$cells was not apparent following co-culture with primary fibroblasts (Supplemental Fig. S4A). The possibility that monocyte/macrophages or
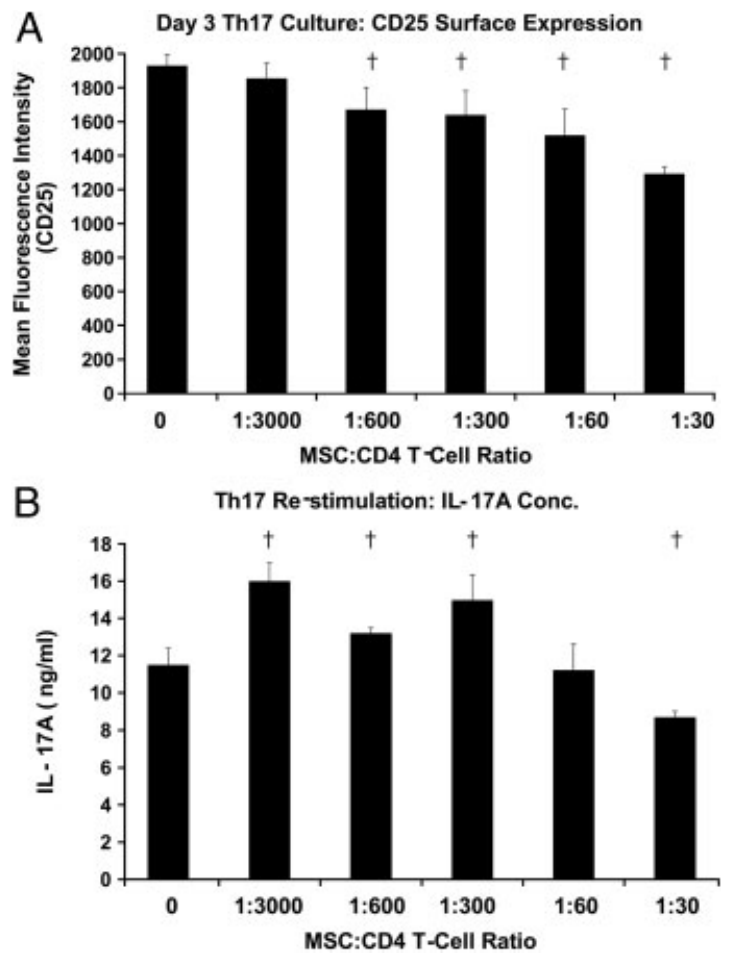

Figure 2. Inhibition of Th17 cells by MSCs is limited in the absence of

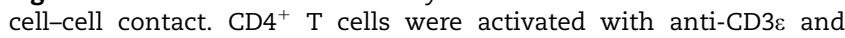
splenic APCs under Th17-skewing conditions separated from B6 MSCs at the indicated ratios in Transwell ${ }^{\mathbb{R}}$ plates. (A) Surface expression of $\mathrm{CD} 25$ on $\mathrm{CD} 4^{+} \mathrm{T}$ cells at day 3 , as measured by flow cytometry. (B) IL17A concentrations in supernatants of re-purified $\mathrm{CD}^{+} \mathrm{T}$ cells re-stimulated for $24 \mathrm{~h}$ with anti-CD3/anti-CD28-coated beads, as measured by ELISA. Data are mean + SD and are representative of three individual experiments. ${ }^{\dagger} p<0.05$ compared with the no MSCs condition, two-tailed, unpaired Student's t-test.

DCs were responsible for indirectly mediating MSC suppressive effects on T-cell responders was eliminated by experiments in which primary $\mathrm{CD} 4^{+}$T-cell/MSC co-cultures were initiated with anti-CD3/anti-CD28-coated beads rather than splenic APCs. In this case, the Th-17-suppressive effect of MSCs for both naïve and memory $\mathrm{CD}^{+} \mathrm{T}$ cells persisted (Supplemental Fig. S4B).

The MSC suppressive effect on primary Th17 induction is mediated by COX-2-dependent soluble factors

In order to identify potential mediators of MSC-induced Th17 suppression, experiments were carried out in which FACSpurified naïve $\mathrm{CD}^{+} \mathrm{T}$ cells were Th17-skewed in APC-free culture (anti-CD3/anti-CD28 beads) in the presence or absence of MSCs (1:200 ratio) with or without blocking/inhibiting factors for candidate mediators. The primary experimental read-out was secretion of IL-17A following overnight stimulation of re-purified CD4 ${ }^{+} \mathrm{T}$ cells. As shown in Fig. 5A, the non-specific COX inhibitor indomethacin reversed the MSC suppressive effect and, in some experiments, was associated with a paradoxical increase. The observation was consistent with induction, via T-cell-MSC contact, of a COX-dependent soluble mediator. To test this 

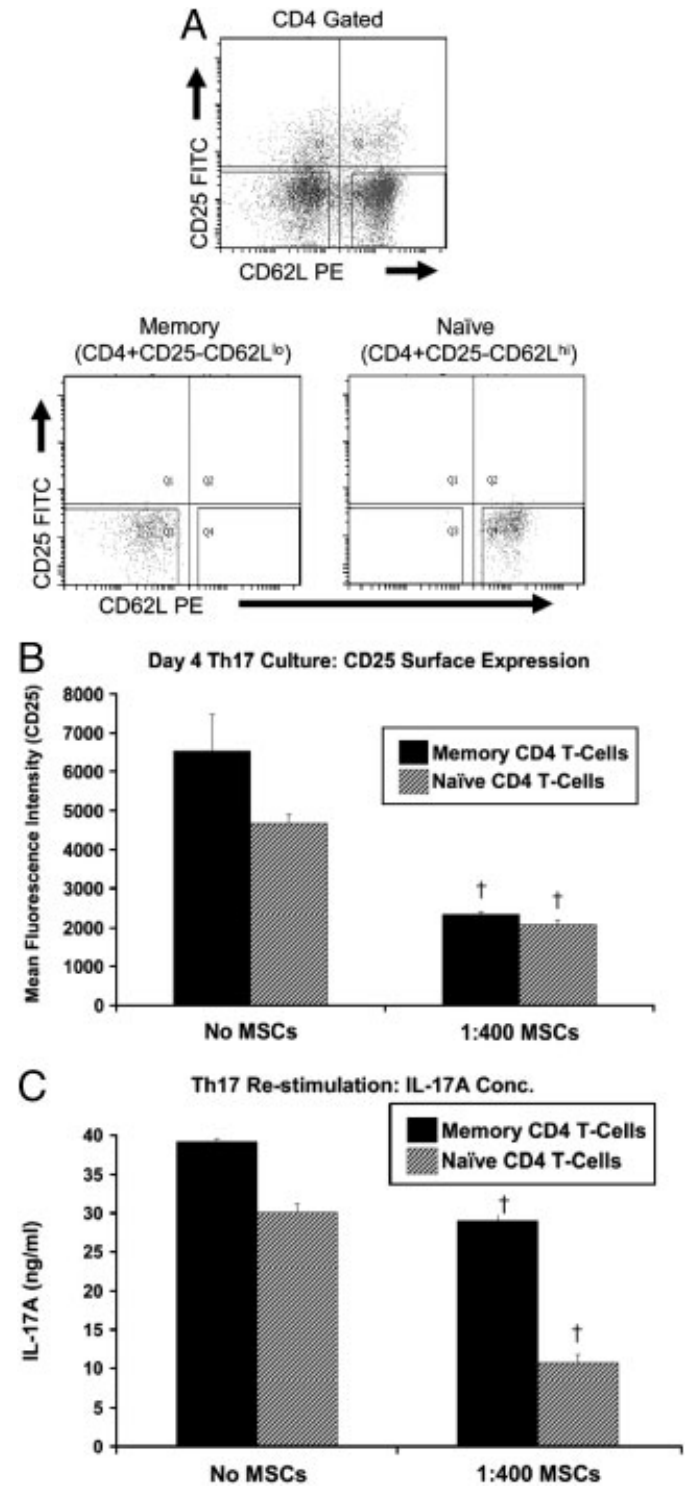

Figure 3. MSC inhibition of Th17 differentiation of naive- and memory-phenotype CD4 ${ }^{+} \mathrm{T}$ cells. (A) Dot plots of $\mathrm{CD} 4^{+} \mathrm{T}$ cells prior to (top) and following (bottom) FACS. (B) Surface-expression of CD25 and (C) IL-17A concentration in supernatants following re-stimulation of memory- and naïve-phenotype $C D 4^{+} \mathrm{T}$ cells following 4 days \pm 1:400 MSCs under Th-17-skewing conditions. (B, C) Data are mean+SD and are representative of five individual experiments. ${ }^{\dagger} p<0.05$ compared with no MSCs condition, two-tailed, unpaired Student's t-test.

further, culture supernatants were removed from 4-day, APC-free Th17 cultures generated with and without indomethacin in the presence or absence of MSCs. These supernatants were applied to newly initiated Th17 cultures along with unconditioned medium and MSC-conditioned medium containing equivalent concentrations of Th17 inducing factors with and without indomethacin (Fig. 5B). $C D 4^{+} \mathrm{T}$ cells were then re-purified from each culture and stimulated overnight, after which IL-17A production was measured. As shown, MSC-conditioned medium was associated with a modest reduction in IL-17A compared with unconditioned
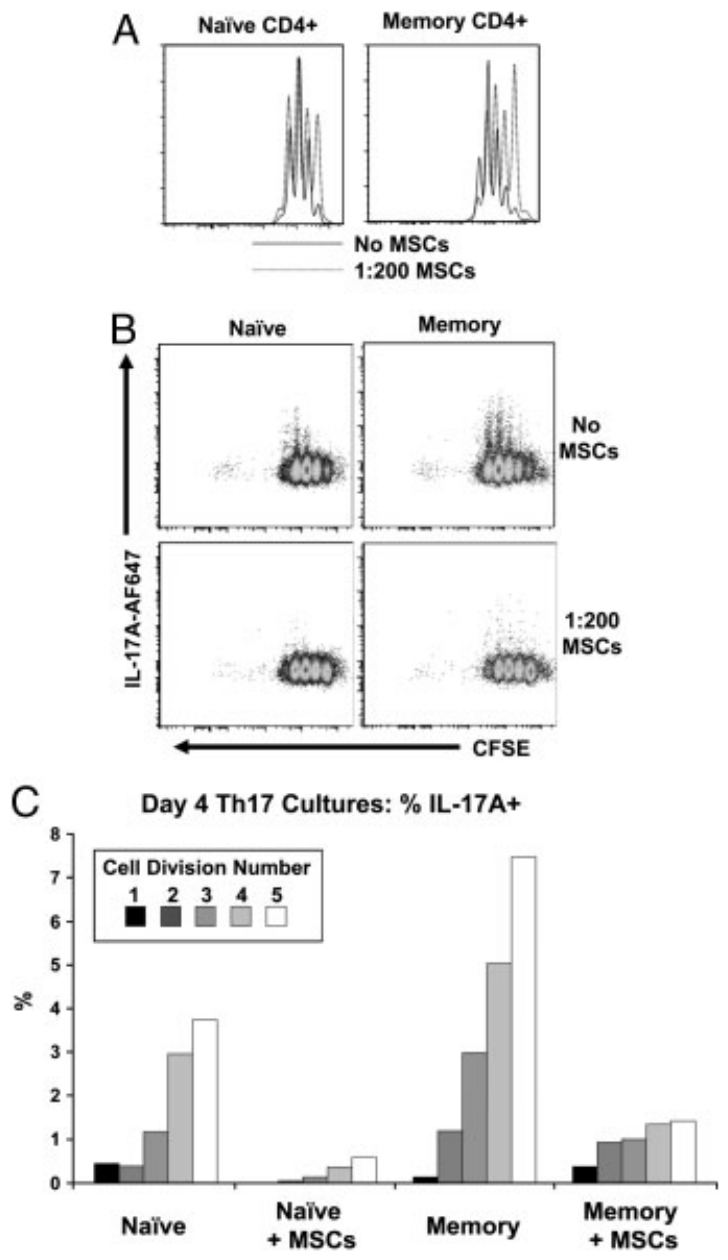

Figure 4. MSC inhibition of Th17 differentiation in relation to T-cell division. FACS-purified naïve- and memory-phenotype $\mathrm{CD}^{+}{ }^{+} \mathrm{T}$ cells were CFSE-labelled and activated with anti-CD3\& plus APCs under Th17-skewing conditions \pm 1:200 MSCs. (A) CFSE dye dilution histograms illustrating $\mathrm{CD} 4^{+} \mathrm{T}$-cell proliferation at day 4. (B) Representative dot plots showing intracellular IL-17A staining relative to CFSE dilution in $\mathrm{CD} 4^{+} \mathrm{T}$ cells at day 4. (C) Graphic representation of the proportions of each $\mathrm{CD} 4^{+} \mathrm{T}$-cell generation that were $\mathrm{IL}-17 \mathrm{~A}^{+}$. Data are representative of three individual experiments.

medium. In contrast, medium from Th17/MSC co-cultures resulted in substantially greater reduction of IL-17A as well as strong inhibition of CD25 up-regulation (data not shown). These effects were entirely or predominantly absent for media derived from indomethacin-containing cultures. Addition of medium from Th17 cultures lacking MSCs had no suppressive effect and was not influenced by indomethacin. Reversal of the MSC suppressive effect on primary Th17 differentiation was also demonstrated using NS-398, a selective COX-2 inhibitor (Fig. 5C). Next, MSCs were FACS-purified from 4-day Th17 co-cultures and subjected to qRT-PCR and Western blotting (Fig. 5D) using COX-1 and COX-2-specific reagents. As shown, specific up-regulation of COX-2 in MSCs co-cultured with $\mathrm{CD}^{+}$ $\mathrm{T}$ cells under Th17-skewing conditions was observed at mRNA and protein level. Blocking/inhibition experiments carried out to examine the role of other candidate mediators (NO, IDO, IL-10, 
CCL2) yielded negative or minimally significant results (data not shown). Overall, these experiments supported a conclusion that the primary mechanism of Th17 suppression from both naïve and memory-phenotype $\mathrm{CD}^{+}{ }^{+} \mathrm{T}$ cells was the production of a prostanoid mediator due to induced up-regulation of COX-2 in MSCs following direct contact between MSCs and activated $\mathrm{T}$ cells.

\section{PGE2 is induced in Th17-MSC co-cultures and suppresses Th17 induction through the EP4 receptor}

As PGE2 has been reported to mediate multiple immune suppressive effects of MSCs [1, 2, 7, 9, 12, 18], supernatants from MSC/Th17 co-cultures of 6-72 h duration were analysed for PGE2 concentration with relevant controls (Fig. 6A). Neither MSCs cultured alone nor $\mathrm{CD}^{+}{ }^{+} \mathrm{T}$ cells cultured with or without Th17-inducing reagents generated high PGE2 levels. In contrast, MSC/T-cell co-cultures under Th17 differentiating conditions had significant accumulation of PGE2 over 12-72 h. Interestingly, increased PGE2 production was also observed from 12 to $24 \mathrm{~h}$ in MSC/T-cell co-cultures lacking Th17-inducing factors but levels declined again between 48 and $72 \mathrm{~h}$. In additional experiments, MSCs were formally confirmed to be the predominant source of PGE2 in MSC/Th17 co-cultures by sorting individual cell populations following $18 \mathrm{~h}$ of co-culture then re-plating them for an additional $18 \mathrm{~h}$ and quantifying PGE2 concentration in the resulting supernatants (Supplementary Figs. S5, S6 and S7A). PGE2 concentration increased in a dose-dependent manner in Th17 cultures involving direct contact with MSCs but not in Transwell ${ }^{\circledR}$ co-cultures at the same MSC:CD4 ${ }^{+}$T-cell ratios (Supplementary Fig. S8A). Additionally, PGE2 concentrations in supernatants from fibroblast/Th17 co-culture supernatants were not different to those of control Th17 cultures (Supplementary Fig. S8B).

It was next determined whether MSC suppressive effects on primary Th17 cultures were mediated by PGE2. Addition of purified PGE2 was associated with a dose-dependent inhibition of T-cell proliferation and IL-17A production (Fig. 6B) as well as of CD25 surface expression and IL-17A production following re-stimulation (data not shown). Inhibition occurred between 2 and 20 nM PGE2 - within the range observed by $12 \mathrm{~h}$ in MSC/ Th17 co-cultures. The role of PGE2 in mediating MSC suppressive effects on Th17 differentiation cultures was confirmed by addition of specific antagonists and agonists for candidate PGE2 receptors. IL-17A secretion by $\mathrm{CD}^{+} \mathrm{T}$ cells re-purified from MSC/Th17 co-cultures was restored to the same level as that of control Th17 cultures by the highly selective EP4 receptor antagonist L-161,982 (Fig. 6C). Similarly, EP4 antagonism reversed the inhibition by MSCs of CD25 up-regulation on $\mathrm{CD}^{+}$ $\mathrm{T}$ cells (data not shown). That this observation was specifically attributable to PGE2 produced by MSCs during co-culture was
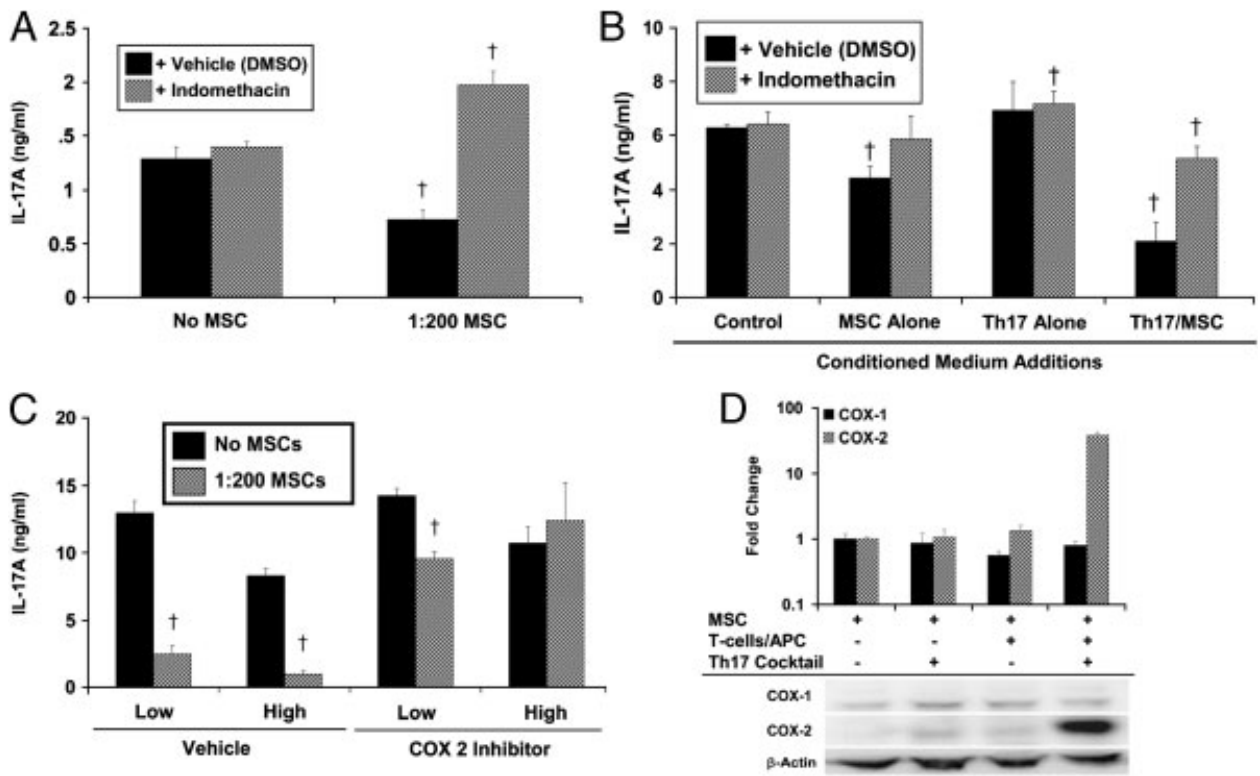

Figure 5. Role of cyclooxygenases in MSC suppression of Th17 differentiation. (A) IL-17A production by FACS-purified, naïve-phenotype CD4 ${ }^{+}$ $\mathrm{T}$ cells activated for 4 days with anti-CD3/anti-CD28 beads under Th17-skewing conditions $\pm 1: 200$ MSCs with vehicle (DMSO) or $5 \mu \mathrm{M}$ indomethacin. Cells were then re-purified and stimulated overnight in equal numbers. (B) IL-17A production by CD $4^{+} \mathrm{T}$ cells stimulated for 4 days by anti-CD3/anti-CD28 beads under Th17-skewing conditions with the addition of various conditioned media then re-purified and stimulated overnight in equal numbers. (C) IL-17A production by $\mathrm{CD}^{+} \mathrm{T}$ cells stimulated for 4 days by anti-CD3/anti-CD28 beads under Th17-skewing conditions $\pm 1: 200 \mathrm{MSCs}$ in the presence of 0.1 (Low) or $1.0 \mu \mathrm{M}$ (High) selective COX-2 inhibitor (NS-398) or equivalent volumes of vehicle then repurified and stimulated overnight in equal numbers. (D) Top: relative mRNA expression of COX-1 and COX-2 in MSCs purified by FACS following 4 days in culture $\pm \mathrm{CD}^{+} \mathrm{T}$ cells/APC and a Th17-inducing cocktail. Results shown are mean $+\mathrm{SD}$ expression level relative to MSCs alone. Bottom: Western blots for COX-1, COX-2 and $\beta$-actin of FACS-purified MSCs from the same culture conditions. (A) is representative of four individual experiments, (B and D) are representative of two individual experiments and (C) is representative of three individual experiments. ${ }^{\dagger} p<0.05$ compared with no MSCs condition (A and C), control medium (B), and MSC alone (D), two-tailed, unpaired Student's t-test. 
A
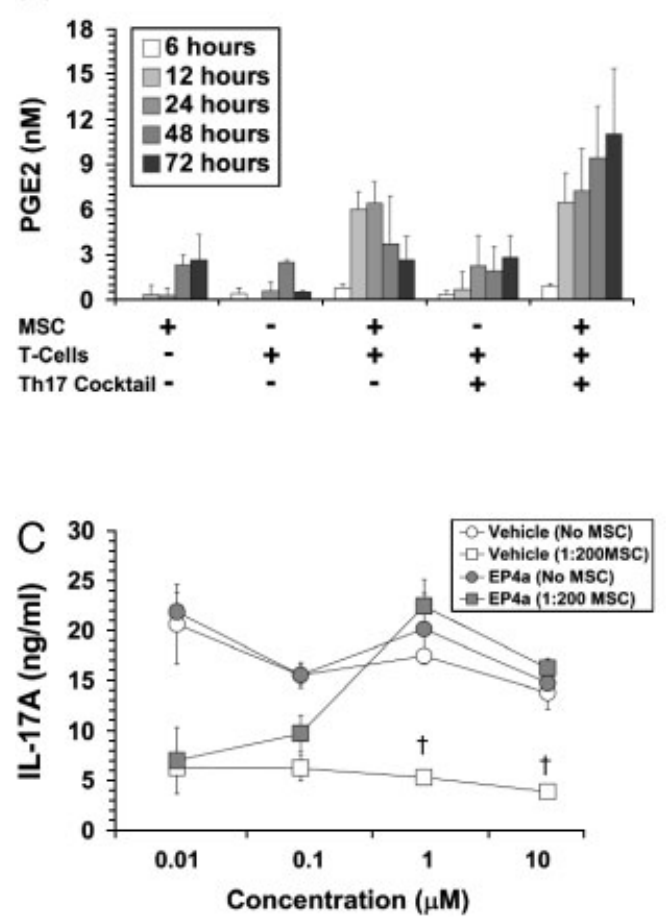
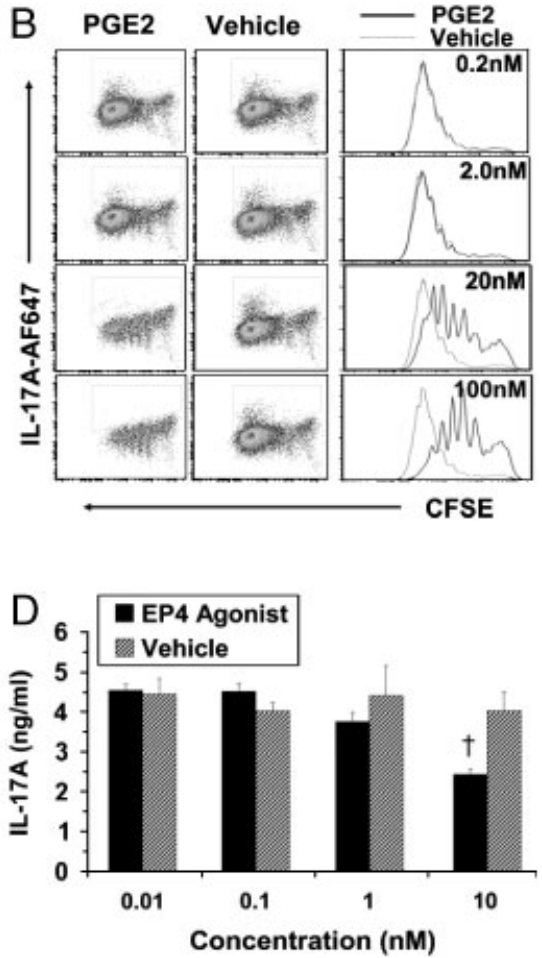

Figure 6. MSC inhibition of Th17 differentiation is provided by PGE2 via EP4 receptor. (A) PGE2 concentrations in culture supernatants following 6, 12, 24, 48 and $72 \mathrm{~h}$ of various MSC and CD4 ${ }^{+}$T-cell cultures and co-cultures. MSC:T-cell ratio was 1:200. The Th17 cocktail consisted of anti-CD3/ anti-CD28-coated beads with Th17-inducing factors. (B) CFSE dilution and intracellular IL-17A analysis following re-stimulation of Th17 cultures initiated with anti-CD3/anti-CD28-coated beads with addition of 0.2-100 nM PGE2. (C) IL-17A production by CD4 ${ }^{+}$T cells stimulated for 4 days by anti-CD3/anti-CD28 beads under Th17-skewing conditions $\pm 1: 200 \mathrm{MSCs}$, with and without varying concentrations of selective EP4 antagonist. Cells were then re-purified and stimulated overnight in equal numbers. (D) IL-17A production by CD4 ${ }^{+} \mathrm{T}$ cells stimulated for 4 days by anti-CD3/ anti-CD28 beads under Th17-skewing conditions with varying concentrations of a selective EP4 agonist or equivalent volumes of vehicle. Cells were then re-purified and stimulated overnight in equal numbers. (A, C and D) Data shown are mean+SD and are representative of (A) five individual experiments, $(B, D)$ three individual experiments and $(C)$ four individual experiments.

confirmed by transfer of conditioned media from FACS-sorted co-culture populations and relevant controls to fresh Th17 cultures in the presence or absence of EP4 antagonist (Supplementary Figs. S5, S6 and S7B). In this case, only medium conditioned by MSCs sorted from Th17/MCS co-cultures transferred a Th17 suppressive effect that was reversible by EP4 antagonism. Experiments carried out with antagonists of the EP1 and EP2 receptors (SC-51322 and AH 6809 respectively) yielded negative results (data not shown). As further evidence of a specific role for PGE2/EP4, the EP4 agonist L-902,688-mediated dose-dependent inhibition of the primary induction of Th17 cells (Fig. 6D).

\section{MSCs suppress IL-17A secretion by effector-memory Th17 cells from acutely obstructed kidney}

Up to this point, the experiments were carried out exclusively with primary naïve and/or memory $\mathrm{CD}^{+} \mathrm{T}$ cells undergoing activation in vitro under short-term Th17-skewing conditions. Making use of a unilateral ureteral obstruction (UUO) model in which we have previously reported intra-renal accumulation of effector-memory phenotype Th17 cells [22], it was determined whether MSCs exert a mechanistically-similar suppressive effect on the re-activation of committed Th17 cells from an area of ongoing tissue inflammation. As shown in Fig. 7A, B6 mice underwent UUO for $72 \mathrm{~h}$ following which CD45 ${ }^{+}$cells were enriched from obstructed and contralateral (non-obstructed) kidneys and briefly stimulated through the T-cell receptor in the absence or presence of MSCs. In-line with our previous findings [22], anti-CD3\&-stimulation was associated with robust secretion of IL-17A by cells from obstructed kidneys (Fig. 7B). The presence of MSCs was associated with dose-dependent reduction in IL-17A concentration following either 24 or $48 \mathrm{~h}$ culture periods. Qualitatively similar results were observed in a total of seven similar experiments with median proportionate inhibition of IL-17A production being 56\% (range 19-69\%) at MSC:CD45 ${ }^{+}$ cell ratio of 1:20. As we have previously reported [22], IL-17A secretion was absent from stimulated cultures of $\mathrm{CD} 45^{+}$cells from non-obstructed kidneys (data not shown). The suppressive effect of MSCs was reversed by indomethacin (Fig. 7C). Thus, naturally occurring effector-memory Th17 cells undergoing activation through the T-cell receptor signalling complex are amenable to suppression by MSCs via a similar COX-2-dependent mechanism. 

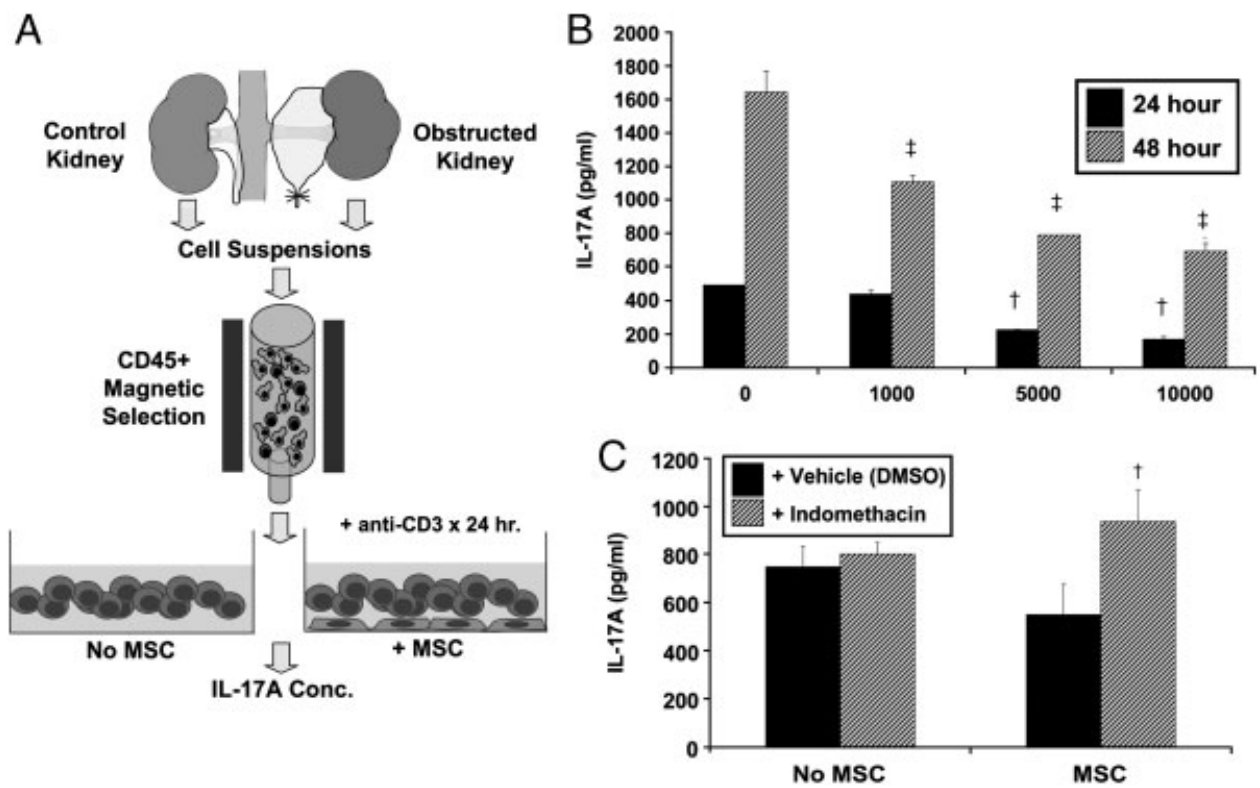

Figure 7. MSC inhibition of in vivo-derived Th17 cells. (A) $C D 45^{+}$leukocytes were purified from obstructed and non-obstructed kidneys and stimulated with low-dose anti-CD3 $\varepsilon \pm$ MSCs followed by IL-17A measurement in culture supernatants. (B) IL-17A production by CD45 ${ }^{+}$cells of obstructed kidneys following 24 and 48 hour culture with $0,1000,5000$, and 10000 MSCs. (C) IL-17A production by CD45 cells of obstructed kidneys following a $24 \mathrm{~h}$ culture $\pm 10000 \mathrm{MSCs}$ with vehicle or $5 \mu \mathrm{M}$ indomethacin. $(\mathrm{B}, \mathrm{C})$ Data shown are mean $+\mathrm{SD}$ and are representative of 7 individual experiments. ${ }^{\dagger} p<0.05$ compared with (A) no MSCs or (B) vehicle at $24 \mathrm{~h}$. ${ }^{\dagger} p<0.05$ compared with no MSCs at $48 \mathrm{~h}$ (A), two-tailed, unpaired Student's t-test.

\section{Discussion}

A decade of in vitro experimentation has established that inhibition of T-cell activation and proliferation is an important element of MSC-mediated immune suppression [1, 2, 11]. Benefits of MSC administration in models of autoimmunity and allotransplantation indicate corresponding in vivo effects [2, 4, $14,32,33]$. Nonetheless, some basic issues regarding MSC/T-cell interactions remain incompletely elucidated including the relative potency of MSC suppression of primary compared with secondary T-cell activation, MSC influence on individual T-cell effector programmes, the relative importance of the wide diversity of mediators that have been linked with T-cell inhibition and the balance between direct T-cell effects and indirect inhibition mediated via APCs.

In the current study we have addressed such issues with a focus on the Th17 differentiation pathway - a pro-inflammatory Th cell effector phenotype with pathogenic potential in a range of immune-mediated diseases [28, 29]. We demonstrate that low numbers of MSCs are capable of suppressing de novo Th17 differentiation through a mechanism that is initiated most potently by MSC/T-cell contact but is subsequently mediated by PGE2 acting via the EP4 receptor. In contrast to other reported T-cell inhibitory phenomena $[17,19]$, we find that IFN- $\gamma$-mediated triggering of MSCs was not necessary for Th17 suppression. Furthermore, we demonstrate suppression by MSCs of Th17 differentiation from both naïve- and memory-phenotype precursors as well as inhibition of IL-17A production by naturally occurring effector-memory Th17 cells in a model of acute tissue inflammation. Our initial observations of MSC effects on in vitro- generated Th17 cells from mouse both confirm and extend results recently reported by Ghannam et al. for human cells [9]. In agreement with this study, we observed that mouse MSCs inhibited the primary differentiation of Th17 cells from naïve precursors and that MSC co-culture resulted in reduced IL-17A production by $\mathrm{T}$ cells during MSC-free re-stimulation [9]. Regarding the question of whether MSC suppressive effects are exerted directly upon $\mathrm{CD}^{+}{ }^{+} \mathrm{T}$ cells undergoing Th17 differentiation, experiments in an APC-culture system effectively rule out an intermediary role for DCs, macrophages or other accessory cells. As only a fraction of the $\mathrm{CD}^{+} \mathrm{T}$ cells within primary cultures were $\mathrm{IL}-17 \mathrm{~A}^{+}$by intracellular staining at a given time, we cannot definitively rule out a role for an additional T-cell population in suppressing the Th17 differentiation programme. Nonetheless, cross-regulation by Th1 or Th2 effectors during primary Th17 induction cultures is highly unlikely given the continuous blockade of IFN- $\gamma$ and IL-4. Furthermore, and in contrast to the findings of Ghannam et al. [9], we did not detect induction of $\mathrm{FOXP}^{+}$or $\mathrm{IL}^{-} 10^{+} \mathrm{T}$ cells in experiments carried out using FACS-purified, naïve-phenotype $\mathrm{CD}^{+} \mathrm{T}$ cells co-cultured with MSCs under Th17-skewing conditions (data not shown).

From a clinical perspective, it is important to consider the degree to which Th17 suppression by MSCs applies to preactivated $\mathrm{T}$ cells and $\mathrm{T}$ cells with pre-existing Th17 imprinting. The results we present here for purified memory-phenotype $\mathrm{CD}^{+}{ }^{+} \mathrm{T}$ cells and for effector-memory Th17 cells derived from obstructed kidney indicate suppression of IL-17A secretion comparable to that of naïve $\mathrm{CD} 4^{+} \mathrm{T}$ cells. In the case of memoryphenotype $\mathrm{CD} 4^{+} \mathrm{T}$ cells activated in vitro under Th17-skewing 
conditions, MSC contact was also associated with inhibition of proliferation and of CD25 up-regulation. These results are in-line with the in vitro and in vivo findings of Rafei et al. for MSC effects on MOG-specific Th17 cells in mouse EAE [14]. In addition, MSC-mediated suppression of Th17 responses has been reported for antigen-specific Th17 cells in rat EAE and autoimmune myasthenia gravis and in established autoimmune diabetes mellitus in NOD mice [32, 33]. Interestingly, however, evidence for enhancement of Th17 differentiation and IL-17A production by MSCs and fibroblasts has also been presented in a small number of studies [34, 35]. The reported results suggested that MSC production of IL- 6 as well as stimulation of IL- 1 and/or IL-23 secretion by APCs were responsible for the observations $[34,35]$. In our own experiments, we have observed that administration of a non-selective COX inhibitor in MSC/Th17 cocultures is associated with enhancement of IL-17A secretion compared with control Th17 cultures (Fig. 5A and our unpublished observation).

We have also confirmed production of IL- 6 and TGF- $\beta 1$ by MSCs co-cultured with activated $\mathrm{T}$ cells (our unpublished observation). Thus, it is important to consider that MSC inhibition of Th17 cell differentiation and activation, while potent, is conditional, being dependent upon opportune MSC/T-cell contact and upon inducible mechanisms which, when absent or subject to blockade, may unmask a paradoxical capacity for enhancement of Th17 activity. Furthermore, in the case of naturally occurring Th17 cells from obstructed kidney (or other sites of inflammation and autoimmunity), additional experimental work will be required to distinguish between direct and indirect MSC effects on this T-cell effector phenotype.

From a mechanistic perspective, we provide compelling evidence that the induced production of PGE2 by MSCs in direct contact with $\mathrm{CD}^{+}{ }^{+} \mathrm{T}$ cells undergoing activation was primarily responsible for suppressive effects on naïve- and memoryphenotype Th17 cells in vitro as well as on in vivo-derived effector-memory Th17 cells. This is consistent with the report of Ghannam et al. in which indomethacin reversed MSC-mediated suppression of Th17 differentiation from human naïve, cordblood CD4 ${ }^{+} \mathrm{T}$ cells as well as IL-17A production by Th17 clones [9]. By utilizing FACS to re-purify MSCs, we convincingly demonstrate significant up-regulation of COX-2 and production of PGE2 by these cells within 12-24h of placement in Th17skewing cultures. We also confirm the role of COX2 using the selective inhibitor NS-398 and illustrate the participation of an induced soluble mediator by medium transfer experiments. Furthermore, we demonstrate that inhibition of Th17 cell proliferation, CD25 up-regulation and IL-17A-secreting capacity are reproducible by synthetic PGE2 at comparable concentrations to those observed in Th17/MSC co-cultures. Finally, results obtained with selective antagonists and agonists for the EP4 receptor in APC-free cultures indicate a direct action of MSCproduced PGE2 on $\mathrm{CD}^{+}{ }^{+} \mathrm{T}$ cells via this receptor. These results highlight the broad role that has been reported for PGE2 in mediating various immune suppressive effects of MSCs [1-3, 6, 7, 9, 12, 18] while also emphasising the fact that high-level production of this, and other, soluble mediators is dependent upon an initial, contact-dependent cross-talk between MSCs and target cells $[2,7,16]$. This latter consideration may be particularly relevant to the variable efficacy of MSCs in human clinical trials [20]. We also note that additional mediators of MSC inhibition of Th17 cells have been reported, primarily in the context of rodent models of tissuespecific autoimmunity, including alternatively cleaved CCL2, IDO and TGF- $\beta 1[14,32,33]$. In the co-culture systems reported here, significant reversal of MSC-mediated Th17 suppression was not observed with blocking/inhibiting agents for these pathways (our unpublished observations) and inhibition of COX-2 was consistently associated with complete or almost complete reversal of suppression. Nonetheless, given the diversity of MSC-associated suppressive mediators that has been identified to date [1-3], it appears likely that additional direct and indirect mechanisms of Th17 inhibition participate under different conditions.

Of relevance to the current study, it is clear from a number of recent reports that the interplay between PGE2, the EP4 receptor and immunological processes, including the Th17 differentiation pathway, is an important but complex one. Xiao et al. demonstrated that both PGE2 and EP4 agonists protect the heart from ischemia reperfusion injury via EP4 [36]. Additionally, Kabashima et al. [37] reported, in a mouse model of colitis that EP4deficient mice develop more severe disease compared with mice deficient in other prostanoid receptors. Complementary results were obtained in animals treated with EP4 antagonist and the effects were associated with increased activation of T cells in the colon of treated animals [37]. In contrast, Yao et al. [38] reported that PGE2 enhanced expansion of Th17 cells in vitro and in vivo through PGE2-EP4 signalling. This effect was mediated, however, indirectly through IL-23 and, in this study, PGE2 was also shown to dose-dependently suppress Th17 differentiation from naïve $\mathrm{CD}^{+}{ }^{+} \mathrm{T}$ cells in an APC-free culture system [38]. Nonetheless, enhancement of Th17-mediated immune responses by PGE2/EP4 signalling has also been described in other experimental settings $[39,40]$. Given the pleiotropic effects and diverse cellular targets of PGE2 in vivo, it appears unlikely that the inhibitory effects of MSC on Th17 cell differentiation and activation can be selectively reproduced in an active disease setting by administration of COX-2 inhibitor or EP4 agonist. Rather, the combined effects of PGE2 and other MSC-associated mediators may be necessary to additionally regulate the production of Th17-promoting factors by ancillary cell populations such as dendritic cells and monocyte/macrophages $[7,12]$.

In conclusion, this study provides novel evidence that MSCderived PGE2 is highly induced in Th17-MSC co-cultures and mediates a potent suppressive effect on primary and secondary Th17 induction via the EP4 receptor. We propose that further characterisation of the interactions between Th17 cells and MSCs, including the nature of the contact-dependent signal responsible for COX-2 up-regulation, will identify additional opportunities for manipulation of the Th17 differentiation program. Furthermore, suppression of IL-17A production by 
effector-memory Th17 cells derived from a site of "sterile inflammation" indicates the potential for MSCs to ameliorate tissue damage associated with maladaptive acute or chronic Th17 activation if delivered in the correct context.

\section{Materials and methods}

\section{Experimental animals and reagents}

Eight- to 12-wk-old female C57BL/6 (B6) and BALB/c mice were purchased from Harlan Laboratories UK (Bicester, UK) and housed in a specific pathogen-free facility. All animal procedures were carried out under licence from the Irish Department of Health and Children and approved by the NUI Galway Animal Care Research Ethics Committee. Mouse MSC cultures were carried out in supplemented Iscove's modified Dulbecco's medium (see Supplemental Methods for details of media and buffer compositions) (Sigma-Aldrich, St. Louis, USA). Th17 cell culture was carried out in supplemented Dulbecco's modified Eagle medium. Reagents used included a range of antibody preparations (see Supplemental Methods), recombinant mouse TGF- $\beta 1$ and IL-6 (Peprotech, Rocky Hill, NJ, USA), mouse CD3/ CD28 T-cell expander beads (Dynabeads ${ }^{\circledR}$, Invitrogen), Indomethacin and PGE2 (Sigma-Aldrich), and COX-2-selective inhibitor (NS-398), selective EP1 antagonist (SC-51322), selective EP2 antagonist (AH 6809), selective EP4 antagonist (L-161,982) and selective EP4 agonist (L-902,688) (all from Cayman Chemicals, Ann Arbor, MI, USA).

\section{MSC isolation and characterisation}

Mouse MSCs were isolated from bone marrow according to the method described by Peister et al. [41]. Tri-lineage differentiation capacity was determined using standard chondrogenic, adipogenic and osteogenic differentiation assays (Supplemental Fig. S1) [18]. All experiments were carried out with passage 5-MSCs grown to $80 \%$ confluence in T175 tissue culture flasks (Nunc-Fisher Scientific) and detached with trypsin solution (Sigma-Aldrich). Renal cortical fibroblasts were prepared according Alvarez et al. [42].

Cortex of kidneys from healthy adult mice was diced and forced through a series of mesh screens $(230 \mu \mathrm{M}, 104 \mu \mathrm{M}$ and $74 \mu \mathrm{M})$ using a glass pestle and washes with Hank's Balanced Salt Solution (all from Sigma-Aldrich). The resulting cell suspensions were re-suspended in F-12 Nutrient mixture (Gibco-Invitrogen) mixed 1:1 with DMEM supplemented with 10\% FCS, 1\% L-glutamine, $1 \%$ penicillin/streptomycin, 1\% HEPES and 1\% nonessential amino acids. The cultured cells were allowed to form colonies in 6-well tissue culture plates (Nunc-Fisher Scientific) for 7 days, then lifted using $0.2 \% \mathrm{Na}_{2}$ EDTA, reseeded into T75 flasks at $1 \times 10^{6} /$ flask and cultured for a further 7 days before use in coculture experiments.

\section{Th17 differentiation cultures}

Single cell suspensions were prepared from mouse spleen and lymph nodes by mechanical disruption and filtering through $150 \mu \mathrm{M}$ Sefar Nitex ribbon mesh (Sefar, Lancashire, UK) followed by erythrocyte lysis in ACK lysis buffer for $3 \mathrm{~min}$ at room temperature. Cell suspensions were incubated with anti-mouse CD4 microbeads (Miltenyi Biotec, Auburn, CA, USA) for $20 \mathrm{~min}$ at $4^{\circ} \mathrm{C}$, washed in MACS buffer and separated using MS columns and an OctoMACS ${ }^{\circledR}$ separator according to the manufacturer's instructions (Miltenyi Biotec). $\mathrm{CD}^{+}$fractions were washed in MACS buffer, re-suspended in culture medium and used as responders in activation cultures. $\mathrm{CD}^{-}$fractions were depleted of remaining $\mathrm{T}$ cells using anti-CD90.2 microbeads by the same protocol and were used as APCs. For Th17 differentiation, CD4 ${ }^{+} \mathrm{T}$ cells and APCs were cultured for 4 days in 96-well round bottom plates (Sarstedt, Nümbrecht, Germany) or for 3 days in the lower compartment of Corning $^{\circledR}$ HTS Transwell ${ }^{\circledR}$ 9-well permeable supports (SigmaAldrich) at $1 \times 10^{6} / \mathrm{mL}$ and $2 \times 10^{6} / \mathrm{mL}$ respectively with $1 \mu \mathrm{g} / \mathrm{mL}$ anti-CD3 $\varepsilon, 5 \mu \mathrm{g} / \mathrm{mL}$ anti-IFN- $\gamma, 4 \mu \mathrm{g} / \mathrm{mL}$ anti-IL-4, $5 \mathrm{ng} / \mathrm{mL}$ TGF- $\beta 1$ and $25 \mathrm{ng} / \mathrm{mL}$ IL-6. In some experiments, $\mathrm{CD}^{+}{ }^{+} \mathrm{T}$ cells were cultured at $1 \times 10^{6} / \mathrm{mL}$ with $1: 1$ Dynabeads ${ }^{\circledR}$. Other reagents were added as described for individual experiments.

For all co-culture experiments, MSCs or fibroblasts were resuspended in DMEM/10\% FCS, added in graded numbers to the wells of 96-well round bottom plates and allowed to adhere for $4 \mathrm{~h}$ prior to the addition of $\mathrm{CD}^{+}{ }^{+} \mathrm{T}$ cells/APCs or $\mathrm{CD}^{+}{ }^{+} \mathrm{T}$ cells/ Dynabeads ${ }^{\circledR}$. For re-stimulation of Th17-skewed $\mathrm{T}$ cells from primary cultures and co-cultures, cells were subjected to magnetic separation using anti-CD4 microbeads with positive column fractions saved. The resulting re-purified $\mathrm{CD}^{+}$ T cells were re-plated at $0.5 \times 10^{6} / \mathrm{mL}$ in fresh medium containing 1:1 Dynabeads ${ }^{\circledR}$ with no other additions in 96-well round bottom plates for a further $24 \mathrm{~h}$. For some experiments, CD4 ${ }^{+}$ $\mathrm{T}$ cells were labelled for analysis of proliferation by flow cytometry using CellTrace CFSE cell proliferation kit (Molecular Probes ${ }^{\circledR}$, Invitrogen). Supernatants from cultures and co-cultures were analysed by ELISA using DuoSet ${ }^{\circledR}$ ELISA Development Systems (R\&D Systems, Minneapolis, MN, USA) for IL-17A and IFN- $\gamma$ and a Parameter Assay Kit for PGE2 (R\&D Systems).

\section{Flow cytometry and FACS}

For flow cytometry, cells were suspended in FACS buffer at $5.0 \times 10^{6} / \mathrm{mL}$, incubated with various combinations of fluorochrome-labelled antibodies for $20 \mathrm{~min}$ at $4{ }^{\circ} \mathrm{C}$, then washed and re-suspended in FACS buffer prior to being analysed using a BD FACSCanto ${ }^{\mathbb{R}}$ cytometer and FlowJo ${ }^{\mathbb{R}}$ software (TreeStar, Olten, Switzerland). For analysis of intracellular IL-17A, Brefeldin A (GolgiPlug ${ }^{\mathbb{B}} 1 \mu \mathrm{L} / \mathrm{mL}$, BD Biosciences) was added to cultures for $8 \mathrm{~h}$ prior to analysis and, following surface staining, intracellular staining was carried out using Cytofix/Cytoperm ${ }^{\circledR}$ reagents. For FACS, magnetic column-enriched $\mathrm{CD}^{+}{ }^{+} \mathrm{T}$ cells were incubated for $20 \mathrm{~min}$ in FACS sorting buffer at $4^{\circ} \mathrm{C}$ with combinations of 
fluorochrome-labelled antibodies then sorted using a BD FACSAriaII ${ }^{\circledR}$ sorter. In some experiments, MSCs were re-purified from co-cultures by FACS based on CD45 surface expression and then subjected to Western Blotting, quantitative RT-PCR or re-cultured to generate conditioned media. Representative examples of gating strategies used for MSC re-purification experiments are provided in Supplementary Fig. S6. Representative gating strategies for additional flow cytometry and FACS experiments are provided in Supplementary Fig. S9. Sorted cells were re-analysed to ensure high purity.

\section{Western blotting}

FACS-purified MSCs were incubated for $1 \mathrm{~h}$ on ice in complete lysis buffer. The protein concentration was determined using a BCA Protein Assay Kit (Fisher Scientific) and proteins were separated on 4-20\% Precise ${ }^{\mathrm{TM}}$ Protein Gels (Fisher Scientific) in a Mini-Protean ${ }^{\circledR}$ Tetra Cell (Bio-Rad, Hercules, CA, USA). Electro-transfer to Immobilion P PVDF membranes (Millipore, Billerica, MA, USA) was performed prior to blocking for $1 \mathrm{~h}$ at room temperature in $5 \% \mathrm{w} / \mathrm{v}$ skimmed milk powder. Membranes were incubated with anti-mouse COX-1 (1:200), anti-mouse COX-2 (1:200) or anti- $\beta$-actin $(1: 50000)$ overnight at $4^{\circ} \mathrm{C}$ followed by washing in TBST, incubation for $1 \mathrm{~h}$ at room temperature with goat anti-rabbit IgG-HRP (1:5000), development using Immobilon ${ }^{\circledR}$ Western Chemiluminescent HRP Substrate (Millipore) and imaging on a Kodak ${ }^{\circledR}$ Image Station 4000MM Pro (Eastman Kodak, Rochester, NY, USA).

\section{Quantitative RT-PCR}

Total RNA was extracted from FACS-purified MSCs using RNeasy Micro kits (Qiagen, Hilden, Germany). Reverse transcription was carried out using the High Capacity cDNA Reverse Transcription kit (Applied Biosystems). Quantitative (Real Time) RT-PCR was performed for murine COX-1 and COX-2 (see Supplemental Methods for primer sequences) using SYBR ${ }^{\circledR}$ Green primer pairs and SYBR $^{\circledR}$ Green PCR Master Mix with 18S rRNA as a normalisation control. Samples were amplified on a Prism 7900HT Real-time PCR System (Applied Biosystems). Relative quantification was performed using the comparative $C_{T}$ method with results expressed as fold difference relative to the MSCsalone sample.

\section{UUO in mice}

UUO with preparation of cell suspensions by collagenase/DNase digestion was conducted as previously described [22, 43] (see also Supplemental Methods). Leukocyte-enriched fractions were prepared from kidney cell suspensions by positive magnetic selection using anti-CD45 microbeads (Miltenyi Biotec). CD45 ${ }^{+}$ cells $\left(2 \times 10^{6} / \mathrm{mL}\right)$ were cultured for $24-48 \mathrm{~h}$ in 96 -well round bottom plates with $0.01 \mu \mathrm{g} / \mathrm{mL}$ anti-CD3 $\varepsilon$ with graded numbers of MSCs and other reagents as described for individual experiments.

\section{Statistical analysis}

Individual experiments were carried out between 2 and 7 times to ensure reproducibility. For culture experiments, individual conditions were generated in replicates of 3-6 and assayed separately. Results were expressed throughout as mean + SD and differences between conditions tested statistically by two-tailed, unpaired Student's $t$-test. Significance was assigned at $p<0.05$.

Acknowledgements: This study was supported by Science Foundation Ireland under grant numbers SFI PI 06/IN.1/B652 (M. D. G), SFI09/SRC/B1794 (M. D. G., J. M. M., F. B., B. P. M. and E. C.), by a Science Foundation Ireland Stoke's Professorship (R. C.) and by the Health Research Board of Ireland under grant number HRB TRA/2007/04 (O. B.).

Conflict of interest: The authors declare no financial or commercial conflict of interest.

\section{References}

1 Uccelli, A., Moretta, L. and Pistoia, V., Mesenchymal stem cells in health and disease. Nat. Rev. Immunol. 2008. 8: 726-736.

2 Griffin, M. D., Ritter, T. and Mahon, B. P., Immunological aspects of allogeneic mesenchymal stem cell therapies. Hum. Gene Ther. 2010. 12: 1641-1655.

3 Barry, F. P., Murphy, J. M., English, K. and Mahon, B. P., Immunogenicity of adult mesenchymal stem cells: lessons from the fetal allograft. Stem Cells Dev. 2005. 14: 252-265.

4 English, K., French, A. and Wood, K. J., Mesenchymal stromal cells: facilitators of successful transplantation? Cell Stem Cell 2010. 7: 431-442.

5 Raffaghello, L., Bianchi, G., Bertolotto, M., Montecucco, F., Busca, A., Dallegri, F., Ottonello, L. and Pistoia, V., Human Mesenchymal Stem Cells Inhibit Neutrophil Apoptosis: A Model For Neutrophil Preservation In The Bone Marrow Niche. Wiley 2008, pp 151-162.

6 Spaggiari, G. M., Capobianco, A., Abdelrazik, H., Becchetti, F., Mingari, M. C. and Moretta, L., Mesenchymal stem cells inhibit natural killer-cell proliferation, cytotoxicity, and cytokine production: role of indoleamine 2,3-dioxygenase and prostaglandin E2. Blood 2008. 111: 1327-1333.

7 Nemeth, K., Leelahavanichkul, A., Yuen, P. S. T., Mayer, B., Parmelee, A., Doi, K., Robey, P. G. et al., Bone marrow stromal cells attenuate sepsis via prostaglandin E2-dependent reprogramming of host macrophages to increase their interleukin-10 production. Nat. Med. 2009. 15: 42-49.

8 English, K., Barry, F. P. and Mahon, B. P., Murine mesenchymal stem cells suppress dendritic cell migration, maturation and antigen presentation. Immunol. Lett. 2008. 115: 50-58.

9 Ghannam, S., Pene, J., Torcy-Moquet, G., Jorgensen, C. and Yssel, H., Mesenchymal stem cells inhibit human Th17 cell differentiation and 
function and induce a T regulatory cell phenotype. J. Immunol. 2010. 185: 302-312.

10 Corcione, A., Benvenuto, F., Ferretti, E., Giunti, D., Cappiello, V., Cazzanti, F., Risso, M. et al., Human mesenchymal stem cells modulate B-cell functions. Blood 2006. 107: 367-372.

11 Bartholomew, A., Sturgeon, C., Siatskas, M., Ferrer, K., McIntosh, K., Patil, S., Hardy, W. et al., Mesenchymal stem cells suppress lymphocyte proliferation in vitro and prolong skin graft survival in vivo. Exp. Hematol. 2002. 30: 42-48.

12 English, K., Ryan, J. M., Tobin, L., Murphy, M. J., Barry, F. P. and Mahon, B. P., Cell contact, prostaglandin E2 and transforming growth factor beta 1 play non-redundant roles in human mesenchymal stem cell induction of CD4+CD25High forkhead box P3+regulatory T cells. Clin. Exp. Immunol. 2009. 156: 149-160.

13 Caplan, A. I. and Dennis, J. E., Mesenchymal stem cells as trophic mediators. J. Cell. Biochem. 2006. 98: 1076-1084.

14 Rafei, M., Campeau, P. M., Aguilar-Mahecha, A., Buchanan, M., Williams, P., Birman, E., Yuan, S. et al., Mesenchymal stromal cells ameliorate experimental autoimmune encephalomyelitis by inhibiting CD4 Th17T cells in a CC chemokine ligand 2-dependent manner. J. Immunol. 2009. 182: 5994-6002.

15 Lee, R. H., Pulin, A. A., Seo, M. J., Kota, D. J., Ylostalo, J., Larson, B. L., Semprun-Prieto, L. et al., Intravenous hMSCs improve myocardial infarction in mice because cells embolized in lung are activated to secrete the anti-inflammatory protein TSG-6. Cell Stem Cell 2009. 5: 54-63.

16 Ren, G., Zhang, L., Zhao, X., Xu, G., Zhang, Y., Roberts, A. I., Zhao, R. C. and Shi, Y., Mesenchymal stem cell-mediated immunosuppression occurs via concerted action of chemokines and nitric oxide. Cell Stem Cell 2008. 2: 141-150.

17 Ryan, J. M., Barry, F., Murphy, J. M. and Mahon, B. P., Interferon- $\gamma$ does not break, but promotes the immunosuppressive capacity of adult human mesenchymal stem cells. Clin. Exp. Immunol. 2007. 149: 353-363.

18 English, K., Barry, F. P., Field-Corbett, C. P. and Mahon, B. P., IFN- $\gamma$ and TNF- $\alpha$ differentially regulate immunomodulation by murine mesenchymal stem cells. Immunol. Lett. 2007. 110: 91-100.

19 Krampera, M., Cosmi, L., Angeli, R., Pasini, A., Liotta, F., Andreini, A., Santarlasci, V. et al., Role for interferon-gamma in the immunomodulatory activity of human bone marrow mesenchymal stem cells. Stem Cells 2006. 24: 386-398.

20 Ankrum, J. and Karp, J. M., Mesenchymal stem cell therapy: two steps forward, one step back. Trends Mol. Med. 2010. 16: 203-209.

21 Ely, L. K., Burrows, S. R., Purcell, A. W., Rossjohn, J. and McCluskey, J., $\mathrm{T}$ cells behaving badly: structural insights into alloreactivity and autoimmunity. Curr. Opin. Immunol. 2008. 20: 575-580.

22 Dong, X., Bachman, L. A., Miller, M. N., Nath, K. A. and Griffin, M. D., Dendritic cells facilitate accumulation of IL-17T cells in the kidney following acute renal obstruction. Kidney Int. 2008. 74: 1294-1309.

23 Ysebaert, D. K., De Greef, K. E., De Beuf, A., Van Rompay, A. R., Vercauteren, S., Persy, V. P. and De Broe, M. E., T cells as mediators in renal ischemia reperfusion injury. Kidney Int. 2004. 66: 491-496.

24 Rasmusson, I., Uhlin, M., Le Blanc, K. and Levitsky, V., Mesenchymal stem cells fail to trigger effector functions of cytotoxic $\mathrm{T}$ lymphocytes. J. Leukoc. Biol. 2007. 82: 887-893.

25 Batten, P., Sarathchandra, P., Antoniw, J. W., Tay, S. S., Lowdell, M. W., Taylor, P. M. and Yacoub, M. H., Human mesenchymal stem cells induce $\mathrm{T}$ cell anergy and downregulate $\mathrm{T}$ cell allo-responses via the $\mathrm{TH} 2$ pathway: relevance to tissue engineering human heart valves. Tissue Eng. 2006. 12: 2263-2273.
26 Li, H., Guo, Z.-K., Li, X.-S., Hou, C.-M., Tang, P.-H. and Mao, N., Functional and phenotypic alteration of intrasplenic lymphocytes affected by mesenchymal stem cells in a murine allosplenocyte transfusion model. Cell Transplant. 2007. 16: 85-95.

27 Lu, X., Liu, T., Gu, L., Huang, C., Zhu, H., Meng, W., Xi, Y. et al., Immunomodulatory effects of mesenchymal stem cells involved in favoring type 2T cell subsets. Transplant Immunol. 2009. 22: 55-61.

28 Bettelli, E., Oukka, M. and Kuchroo, V. K., TH-17 cells in the circle of immunity and autoimmunity. Nat. Immunol. 2007. 8: 345-350.

29 Mills, K. H. G., Induction, function and regulation of IL-17-producing T cells. Eur. J. Immunol. 2008. 38: 2636-2649.

30 Turner, J.-E., Paust, H.-J., Steinmetz, O. M. and Panzer, U., The Th17 immune response in renal inflammation. Kidney Int. 2010. 77: 1070-1075.

31 Paust, H.-J., Turner, J.-E., Steinmetz, O. M., Peters, A., Heymann, F., Holscher, C., Wolf, G. et al., The IL-23/Th17 axis contributes to renal injury in experimental glomerulonephritis. J. Am. Soc. Nephrol. 2009. 20: 969-979.

32 Wang, J., Wang, G., Sun, B., Li, H., Mu, L., Wang, Q., Li, G. et al., Interleukin-27 suppresses experimental autoimmune encephalomyelitis during bone marrow stromal cell treatment. J. Autoimmun. 2008. 30: 222-229.

33 Zhao, W., Wang, Y., Wang, D., Sun, B., Wang, G., Wang, J., Kong, Q. et al., TGF- $\beta$ expression by allogeneic bone marrow stromal cells ameliorates diabetes in NOD mice through modulating the distribution of $\mathrm{CD} 4+\mathrm{T}$ cell subsets. Cell. Immunol. 2008. 253: 23-30.

34 Guo, Z., Zheng, C., Chen, Z., Gu, D., Du, W., Ge, J., Han, Z. and Yang, R., Fetal BM-derived mesenchymal stem cells promote the expansion of human Th17 cells, but inhibit the production of Th1 cells. Eur. J. Immunol. 2009. 39: $2840-2849$.

35 Schirmer, C., Klein, C., von Bergen, M., Simon, J. C. and Saalbach, A., Human fibroblasts support the expansion of IL-17-producing T cells via up-regulation of IL-23 production by dendritic cells. Blood 2010. 116: 1715-1725.

36 Xiao, C.-Y., Yuhki, K.-i., Hara, A., Fujino, T., Kuriyama, S., Yamada, T., Takayama, K. et al., Prostaglandin E2 protects the heart from ischemiareperfusion injury via its receptor subtype EP4. Circulation 2004. 109: 2462-2468.

37 Kabashima, K., Saji, T., Murata, T., Nagamachi, M., Matsuoka, T., Segi, E., Tsuboi, K. et al., The prostaglandin receptor EP4 suppresses colitis, mucosal damage and CD4 cell activation in the gut. J. Clin. Invest. 2002. 109: 883-893.

38 Yao, C., Sakata, D., Esaki, Y., Li, Y., Matsuoka, T., Kuroiwa, K., Sugimoto, Y. and Narumiya, S., Prostaglandin E2-EP4 signaling promotes immune inflammation through TH1 cell differentiation and TH17 cell expansion. Nat. Med. 2009. 15: 633-640.

39 Boniface, K., Bak-Jensen, K. S., Li, Y., Blumenschein, W. M., McGeachy, M. J., McClanahan, T. K., McKenzie, B. S. et al., Prostaglandin E2 regulates Th17 cell differentiation and function through cyclic AMP and EP2/EP4 receptor signaling. J. Exp. Med. 2009. 206: 535-548.

40 Chizzolini, C., Chicheportiche, R., Alvarez, M., de Rham, C., Roux-Lombard, P., Ferrari-Lacraz, S. and Dayer, J.-M., Prostaglandin E2 synergistically with interleukin-23 favors human Th17 expansion. Blood 2008. 112: 3696-3703.

41 Peister, A., Mellad, J. A., Larson, B. L., Hall, B. M., Gibson, L. F. and Prockop, D. J., Adult stem cells from bone marrow (MSCs) isolated from different strains of inbred mice vary in surface epitopes, rates of proliferation, and differentiation potential. Blood 2004. 103: 1662-1668. 
42 Alvarez, R., Sun, M., Haverty, T., Lozzo, R., Myers, J. and Neilson, E., Biosynthetic and proliferative characteristics of tubulointerstitial fibroblasts probed with paracrine cytokines. Kidney Int. 1992. 41: 14-23.

43 Dong, X., Swaminathan, S., Bachman, L. A., Croatt, A. J., Nath, K. A. and Griffin, M. D., Resident dendritic cells are the predominant TNF-secreting cell in early renal ischemia-reperfusion injury. Kidney Int. 2007. 71: 619-628.

Abbreviations: B6: C57BL/6 - MSC: mesenchymal stem cell - PGE2: prostaglandin E2 . UUO: unilateral ureteral obstruction
Full correspondence: Prof. Matthew D. Griffin, REMEDI, NCBES, Orbsen Building, National University of Ireland, Galway, Galway, Ireland Fax: +353-91-495547

e-mail: matthew.griffin@nuigalway.ie

Received: $11 / 2 / 2011$

Revised: 30/5/2011

Accepted: 21/6/2011

Accepted article online: 24/6/2011 